UCRL-100717 Rev 1

PREPRINT

\title{
Impact Studies of Five Ceramic Materials and Pyrex
}

\author{
J. E. Reaugh, A. C. Holt, M. L. Wilkins, B. J. Cunningham, \\ B. L. Hord, A. S. Kusubov
}

This paper was prepared for submittal to the Hypervelocity Impact Symposium

Huntsville, AL

November 16-20, 1998

May 22, 1998

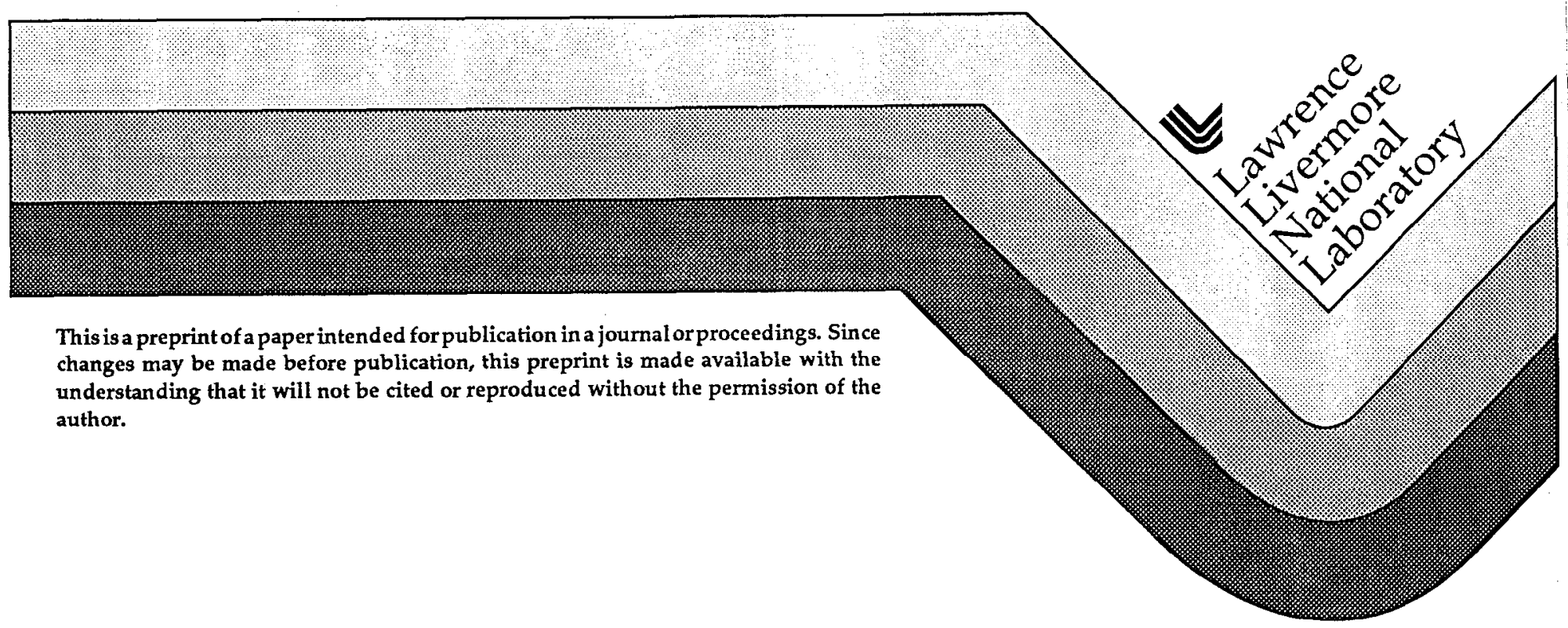




\section{DISCLAIMER}

This document was prepared as an account of work sponsored by an agency of the United States Government. Neither the United States Government nor the University of California nor any of their employees, makes any warranty, express or implied, or assumes any legal liability or responsibility for the accuracy, completeness, or usefulness of any information, apparatus, product, or process

disclosed, or represents that its use would not infringe privately owned rights. Reference herein to any specific commercial product, process, or service by trade name, trademark, manufacturer, or otherwise, does not necessarily constitute or imply its endorsement, recommendation, or favoring by the United States Government or the University of California. The views and opinions of authors expressed herein do not necessarily state or reflect those of the United States Government or the University of California, and shall not be used for advertising or product endorsement purposes. 


\title{
Impact Studies of Five Ceramic Materials and Pyrex
}

\author{
J. E. Reaugh, A. C. Holt, M. L. Wilkins, B. J. Cunningham, \\ B. L. Hord, and A. S. Kusubov
}

\section{Lawrence Livermore National Laboratory Livermore, CA 94550}

\begin{abstract}
We measured the ballistic performance of five ceramic materials (alumina, silicon carbide, boron carbide, aluminum nitride, and titanium diboride) and Pyrex, when they are backed by thick steel plates. The projectile for all tests was a rightcircular cylinder of tungsten sinter-alloy W2 with length $25.4 \mathrm{~mm}$ and diameter 6.35 $\mathrm{mm}$, fired at velocities from 1.35 to $2.65 \mathrm{~km} / \mathrm{s}$. For this threat we determined the minimum areal density of each material that is needed to keep the projectile from penetrating the backup steel. For all of the facing materials studied here, this performance measure increases approximately linearly with projectile velocity. However, the rate of increase is significantly lower for aluminum nitride than for the other materials studied. Indeed, aluminum nitride is a poor performer at the lowest velocity tested, but is clearly the best at the highest velocity. Our computer simulations show the significant influence of the backing material on ceramic performance, manifested by a transition region extending two projectile diameters upstream from the material interface. Experiments with multiple material layers show that this influence also manifests itself through a significant dependence of ballistic performance on the ordering of the material layers.
\end{abstract}

\section{Introduction}

Ceramics, when used appropriately, can stop a variety of projectiles with less weight per unit area than ballistic steel. The design of ceramic composite armor to stop projectiles and the design of laboratory targets to examine the ballistic behavior of ceramic materials is complicated by the characteristic properties of ceramics -- strength in compression and weakness in tension. In the late $60^{\prime} \mathrm{s}$ and 
early $70^{\prime}$ s, Wilkins and colleagues ${ }^{1-5}$ demonstrated that both properties are important to the defeat of small caliber $(7.6 \mathrm{~mm})$ armor-piercing projectiles, and that no single property would correlate ballistic performance for all scenarios. His observations explained why different laboratory targets, which are intended to examine ceramic behavior and which may weight tensile and compressive behavior differently, can produce different rankings among the candidate facing materials. The implication is that one who wishes to measure the ballistic performance of ceramics needs to consciously select a target configuration and projectile combination that tests the particular properties of interest.

For the study reported here, we chose a target configuration that is simple, and that tests the behavior of a facing material when it is well-supported by thick ballistic steel. This eliminates the complex influence of back-plate flexure on ceramic performance.

The projectile chosen is not intended to mimic any specific fielded projectile. It has an aspect ratio $(\mathrm{L} / \mathrm{D}$, where $\mathrm{L}$ is the projectile length and $\mathrm{D}$ is the projectile diameter) of 4 , which is intermediate between short projectiles and long rods. It exhibits features of both long rods (quasi-steady penetration) and short projectiles (unsteady end-of-penetration described by Wilkins and Reaugh ${ }^{6}$ ) With this choice, we were able to defeat the projectile in the velocity range of interest with tile thicknesses of less than about half the lateral dimensions of the tiles available to us. 


\section{Experimental Procedure}

Our targets consisted of square tiles of facing material, $102 \mathrm{~mm}$ on a side, bonded onto the face of square steel backup plates, $152 \mathrm{~mm}$ on a side and $64 \mathrm{~mm}$ thick. A photograph of a typical target is shown in Fig. 1. The ceramic tiles were supplied by Dow Chemical Corporation. The Pyrex was of commercial grade. Densities and sound velocities of the facing materials are given in Table 1 . We chose 4340 steel hardened to Rc35 as our backing material. This steel was chosen over rolled homogeneous armor (RHA) because of the variability in mechanical properties that we have experienced in RIIA in the past. The measured harnesses of our steel backing plates varied from Rc33 to Rc37. The other mechanical properties of the backing steel are given in Appendix A. We expect that the performance of the ceramic facings on this steel will be the same as on RHA. In preparation for target assembly, one side of each steel backup plate was milled lightly to insure a flat, clean and slightly roughened mounting surface. Tile surfaces to be bonded were ground flat and parallel to a tolerance of less than $0.03 \mathrm{~mm}$. Surfaces to be bonded were cleaned with hexane to remove any traces of grease. To insure optimal bonding strength the steel block and ceramic tiles to be assembled were heated to approximately $40^{\circ} \mathrm{C}$ using infrared lamps. The components of the adhesive, Stycast 1266 , were carefully weighed, mixed,

Table 1. Densities and sound velocities of ceramic facing materials

\begin{tabular}{lccc}
\hline Ceramic & $\begin{array}{c}\text { Longitudinal } \\
\text { propagation velocity } \\
\mathbf{k m} / \mathbf{s}\end{array}$ & $\begin{array}{c}\text { Shear propagation } \\
\text { velocity }{ }^{\mathrm{a}} \mathbf{k m} / \mathbf{s}\end{array}$ & Density, g/cc \\
\hline Alumina AD96 & 10.10 & 5.97 & 3.75 \\
Alumina AD85 & $8.80^{\mathrm{c}}$ & 5.07 & 3.40 \\
$\mathrm{SiC}$ & 11.76 & 7.51 & 3.16 \\
$\mathrm{~B} 4 \mathrm{C}$ & 13.83 & 8.72 & 2.51 \\
$\mathrm{AlN}$ & 10.76 & 6.33 & 3.25 \\
$\mathrm{TiB2}$ & 11.08 & 7.43 & 4.49 \\
Pyrex & $5.64^{\mathrm{b}}$ & $3.28^{\mathrm{b}}$ & 2.23 \\
\hline
\end{tabular}

${ }^{a}$ Averaged from several samples of varying thickness

${ }^{b}$ From the AIP handbook, Reference ${ }^{7}$

c From Reference 3 


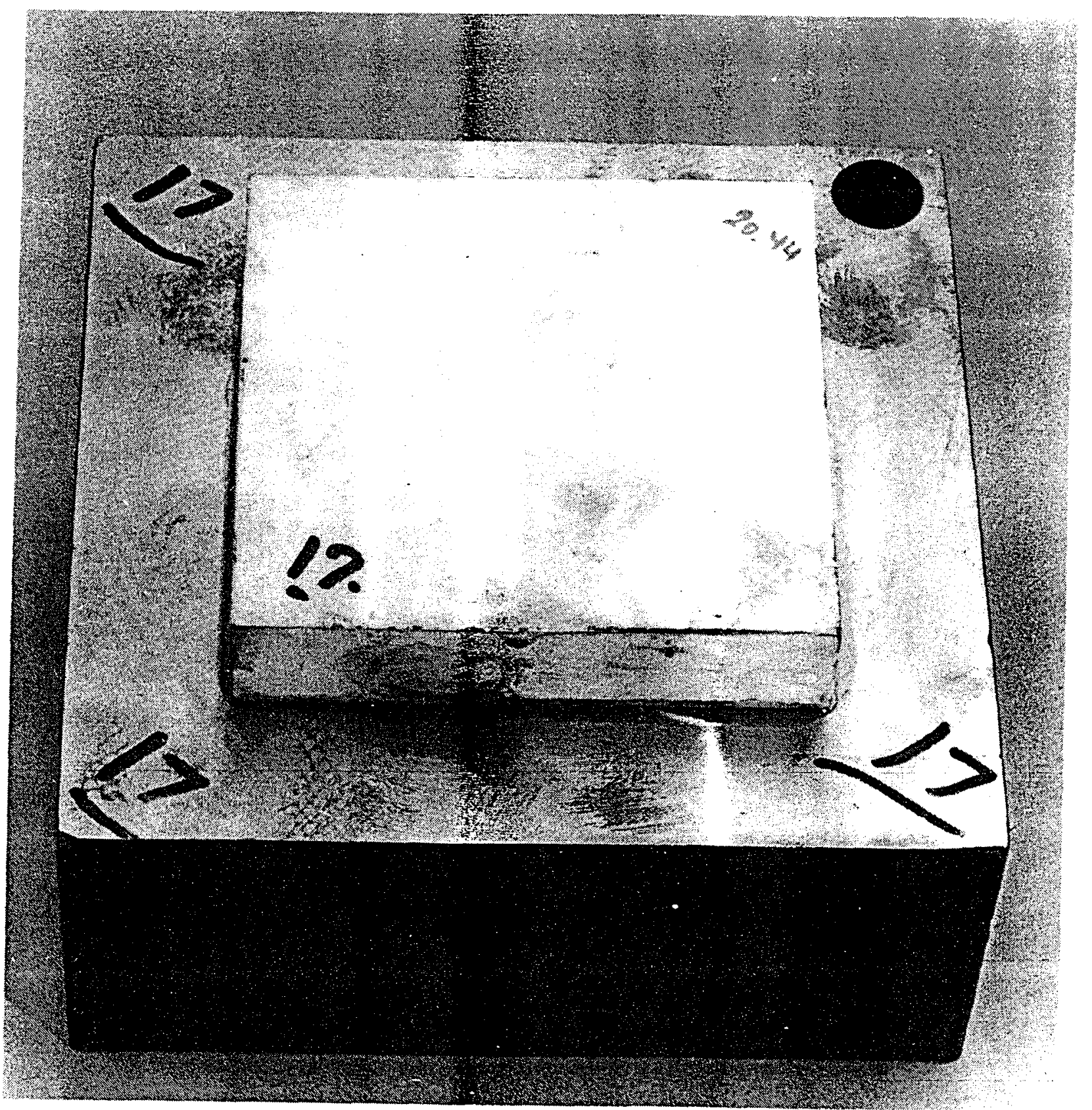

Eigure 1.

Target assembly with ceramic tile bonded to the face of a 4340 steel backup plate. 
and applied to the prepared surfaces. The tiles were then placed on the center of the backup plates. In some cases a single tile was used to produce a target. In others, several tiles were stacked to yield the required facing thickness. Thirty pound weights were placed on top of the tiles being glued to insure a minimal, adhesive layer thickness between the surfaces. The assemblies were then allowed to cure for 24 hours before they were handled.

The projectile was a right circular cylinder, $\mathrm{D}=6.35 \mathrm{~mm}$, and $\mathrm{L}=25.4 \mathrm{~mm}$ of tungster sinter-alloy W2, rianufäctured by GTE. The manufacturer's technical specifications for the mechanical properties of $\mathrm{W} 2$ are given in Table 2.

Our experiments were performed at three nominal velocities: $1.35,1.75$, and $2.6 \mathrm{~km} / \mathrm{s}$. The experiments at 1.35 and $1.75 \mathrm{~km} / \mathrm{s}$ were performed using a 14.5 $\mathrm{mm}$ powder gun and a $23 \mathrm{~mm}$ powder gun respectively, at the Lawrence Livermore National Laboratory (LLNL) ballistic range facility. The LLNL twostage light gas gun was used to accelerate the projectiles for the $2.6 \mathrm{~km} / \mathrm{s}$ experiments. The shots at $1.35 \mathrm{~km} / \mathrm{s}$ were fired into air at 1 atmosphere. In the other shots, the projectiles were fired into a vacuum of about 1 Tor. The sabot assembly was stripped from the projectile by a block of low-density foam. A photograph of a projectile, launch packages, a stripper and cover plate for the $14.5 \mathrm{~mm}$ and $23 \mathrm{~mm}$ guns is shown in Fig. 2. Flash $\mathrm{x}$-rays were used to determine tilt and projectile velocity, as well as to verify that the sabot assembly had been separated from the projectile. Average projectile tilt for a representative sample of experiments was less than 2 degrees. Any tilt greater than 4 degrees was considered excessive and the experiment was repeated.

Table 2. Material properties of W2 Tungsten alloy

\begin{tabular}{lc}
\hline Property & Value \\
\hline Density g/cc & 18.36 \\
Hardness, Rc & 28 to 31 \\
Ultimate tensile strength, kbar & 8.80 \\
Yield strength, kbar & 6.95 \\
Elongation at failure, \% & 5.5 \\
\hline
\end{tabular}




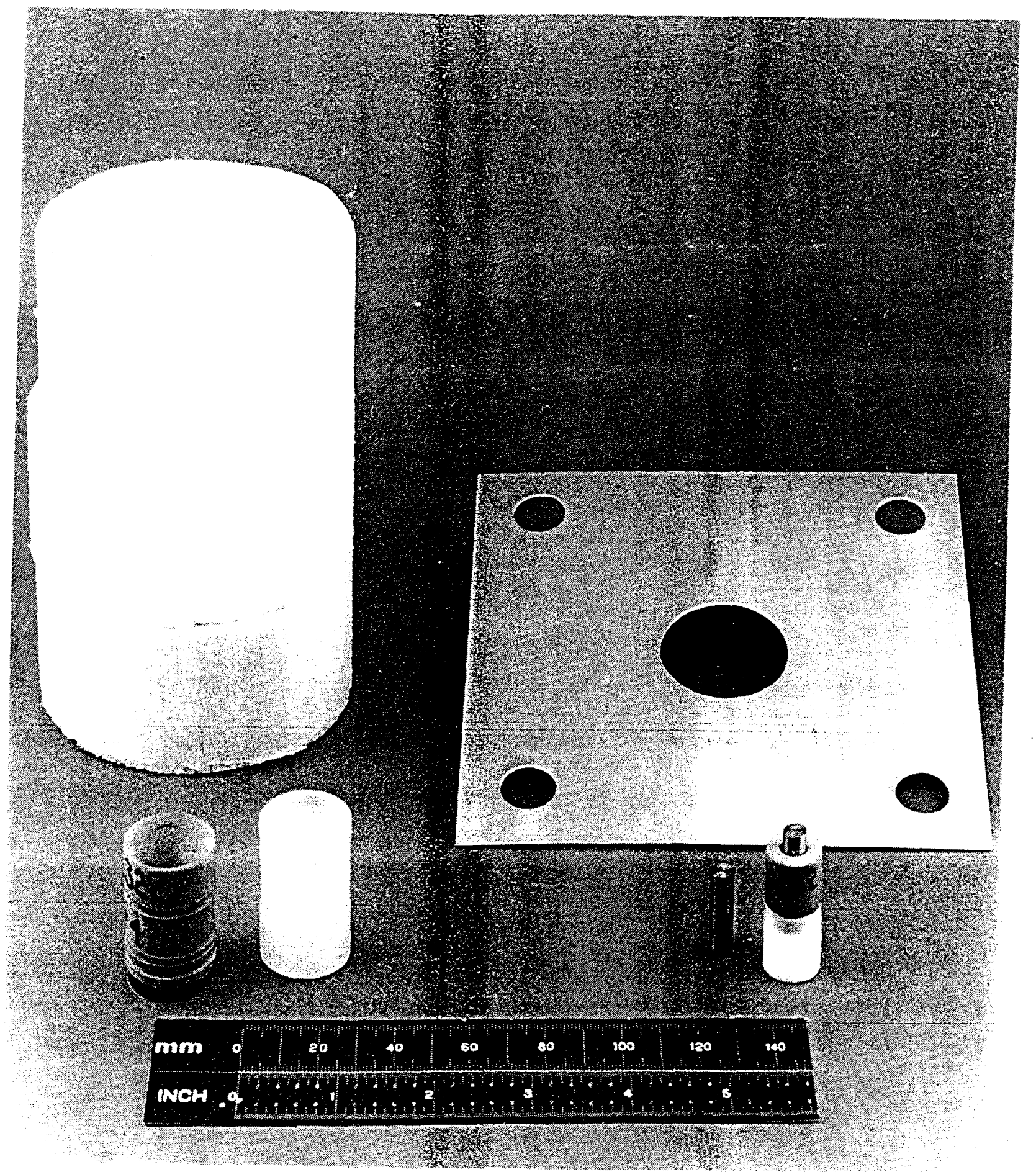

Eigure 2. Projectile/sabot assemblies and sabot stripper with face
plate. 
The depth of penetration into the steel backup plate, normal to the impact surface, $P_{b}$, was used as a performance measure for each shot. Two methods were used for measuring $P_{b}$. The first consisted of measuring the perpendicular distance form the upper surface of the block to the bottom of the crater using a micrometer depth gauge. An inverted U-shaped spacer was employed to straddle the distorted region around the crater opening and to facilitate referencing to the undistorted region of the front face. After measuring the distance from the top of the spacer to the bottom of the crater, the spacer thickness was subtracted to give the hole depth. The end of the depth gauge used is flat with a diameter of $3.2 \mathrm{~mm}$. If the crater was too deep for the first method, or if it were suspected that significant amounts of residual penetrator was present at the bottom of the crater, the steel block was sectioned. Normal depth of penetration was then determined by using a caliper to measure the distance from the deepest point of the projectile penetration to the rear surface of the backup plate and subtracting that value from the (undistorted) backup plate thickness.

\section{Experimental results}

Our measured values of $P_{b}$ are given in Appendix A. Since we measured the penetration depth into the backup plate as a function of facing thickness, we can estimate the minimum facing thickness necessary to prevent penetration of the backup plate, $\Delta^{*}$. To this end, we performed a linear regression fit of $\mathrm{P}_{\mathrm{b}}$ as a function of facing thickness for each material at each nominal velocity. The fit can then be used to solve for $\Delta^{*}$. The results are given in Table 3, and plotted in Fig. 3. In that figure we see that the limiting areal density for each ceramic increases approximately linearly with velocity, and that the various ceramics have different rates of increase. In particular, the limiting areal density of aluminum nitride has the slowest increase with velocity of all the materials tested. As a consequence, it is the best of the ceramics tested at high velocity, i.e. requires the least areal density to stop the projectile. 
Table 3. Linear regression fit to normal impact data, $P_{b}=P_{0}-a \Delta$, for values of the tile thickness $\Delta$ exceeding $10 \mathrm{~mm}$. The average velocity of the experiments used for the fit is $\mathrm{v}$.

\begin{tabular}{lccccccccc}
\hline & \multicolumn{3}{c}{ Low velocity } & \multicolumn{3}{c}{ Intermediate velocity } & \multicolumn{3}{c}{ High velocity } \\
Tile & $\mathbf{P}_{\mathbf{0}} \mathbf{~ m m}$ & $\mathbf{a}$ & $\mathbf{v}, \mathbf{k m} / \mathbf{s}$ & $\mathbf{P}_{\mathbf{0}} \mathbf{m m}$ & $\mathbf{a}$ & $\mathbf{v}, \mathbf{k m} / \mathbf{s}$ & $\mathbf{P}_{\mathbf{0}} \mathbf{~ m m}$ & $\mathbf{a}$ & $\mathbf{v}, \mathbf{k m} / \mathbf{s}$ \\
\hline AD85 & 17.7 & 0.44 & 1.36 & 31.2 & 0.68 & 1.76 & 50.8 & 0.80 & 2.50 \\
AD96 & 19.5 & 0.52 & 1.36 & 31.3 & 0.77 & 1.70 & 54.1 & 0.93 & 2.63 \\
AIN & 18.0 & 0.68 & 1.29 & 36.4 & 1.01 & 1.79 & 55.5 & 1.20 & 2.60 \\
$\mathrm{~B}_{\mathbf{4}} \mathrm{C}$ & 33.9 & 1.98 & 1.25 & 38.9 & 1.01 & 1.77 & 32.1 & 0.45 & 2.61 \\
Pyrex & --- & --- & -- & 33.2 & 0.59 & 1.79 & 53.2 & 0.63 & 2.65 \\
$\mathrm{SiC}$ & 37.2 & 2.33 & 1.37 & 35.5 & 1.05 & 1.72 & 38.9 & 0.64 & 2.65 \\
$\mathrm{TiB}_{\mathbf{2}}$ & 44.2 & 4.05 & 1.35 & 41.6 & 2.09 & 1.70 & 60.4 & 1.30 & 2.65 \\
\hline
\end{tabular}

We wondered whether stacking several facing plates to obtain a desired thickness would give a different result in our experiments than if the facing had been a single plate of the same thickness as the total. In order to investigate this question, we repeated the silicon carbide shot at $1.75 \mathrm{~km} / \mathrm{s}$ with $20 \mathrm{~mm}$ of facing. In the original shot, we used a single $20 \mathrm{~mm}$ thick tile as facing, and in the second, we stacked two $10 \mathrm{~mm}$ plates. The difference in the results was insignificant.

Our simulations, discussed below, suggested that if two layers of different facing materials are used over the steel backup plate, then the order in which

Table 4. Experimental results for $25.4 \mathrm{~mm}$ by $6.35 \mathrm{~mm}$ diameter tungsten cylinder into steel faced by multiple ceramic plates at normal obliquity.

\begin{tabular}{lllccc}
\hline \multicolumn{1}{c}{ Material } & $\begin{array}{c}\text { Upper plate } \\
\text { Thickness, } \\
\text { mm }\end{array}$ & \multicolumn{1}{c}{ Material } & $\begin{array}{c}\text { Thickness, } \\
\text { mm }\end{array}$ & $\begin{array}{c}\text { Projectile } \\
\text { velocity, } \\
\mathbf{k m} / \mathbf{s}\end{array}$ & $\begin{array}{c}\text { Penetration } \\
\text { into steel, } \\
\text { mm }\end{array}$ \\
\hline $\mathrm{AD} 96$ & 10.2 & $\mathrm{TiB}_{2}$ & 10.0 & 1.78 & 16.1 \\
$\mathrm{TiB}_{2}$ & 10.1 & $\mathrm{AD}_{2}$ & 10.2 & 1.76 & 13.9 \\
Pyrex & 13.7 & $\mathrm{TiB}_{2}$ & 14.8 & 1.78 & 12.6 \\
$\mathrm{TiB}_{2}$ & 14.7 & Pyrex & 13.8 & 1.77 & 4.8 \\
$\mathrm{TiB}_{2}$ & 10.0 & Pyrex & 18.5 & 1.77 & 11.9 \\
\hline
\end{tabular}


they occur might strongly influence their performance. In order to see if this is so, we performed a series of experiments in which titanium diboride plates were used in combination with Pyrex and with AD96 plates. In each case, shots were performed with the $\mathrm{TiB}_{2}$ next to the steel and then again, with the $\mathrm{TiB}_{2}$ on the front face. The results of these experiments are given in Table 4 . They show a strong dependence on the ordering of the facing materials.

For example, the first pair of experiments in Table 4 utilized $10 \mathrm{~mm}$ plates of $\mathrm{AD} 96$ and $\mathrm{TiB}_{2}$. With these thin piates, the results were almost identical. The total areal densities penetrated were $20.9 \mathrm{~g} / \mathrm{cc}$ and $19.2 \mathrm{~g} / \mathrm{cc}$. With $20 \mathrm{~mm}$ of $\Lambda \mathrm{D} 96$ at the same nominal velocity, the areal density penetrated was $19.8 \mathrm{~g} / \mathrm{cc}$. Clearly the $\mathrm{TiB}_{2}$ did not perform well when supported by AD96. In fact, its behavior was AD96-like. In the second pair of experiments we used thicker plates of $\mathrm{TiB}_{2}$ and Pyrex. With Pyrex on the outside, the areal density penetrated was $19.5 \mathrm{~g} / \mathrm{cc}$, a

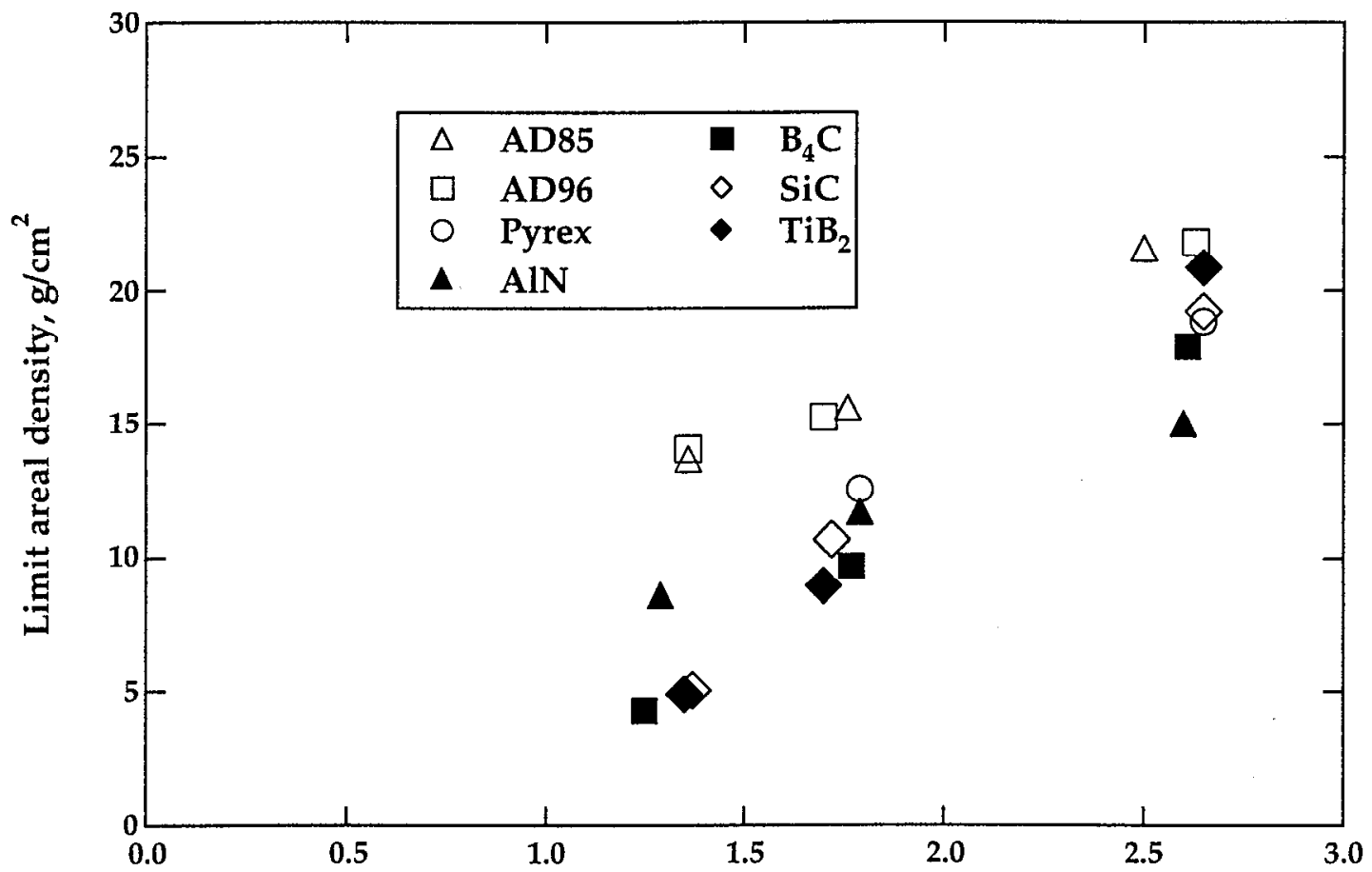

Projectile velocity, $\mathrm{km} / \mathrm{s}$

Figure 3. The limit areal density required to prevent penetration in the backup steel, calculated from fits to the experimental data. 
performance worse than either of the materials used alone. On the other hand, with $\mathrm{TiB}_{2}$ outside, ate areal density penetrated was $13.4 \mathrm{~g} / \mathrm{cc}$, which is better than Pyrex alone and somewhat worse than $\mathrm{TiB}_{2}$ alone. Finally, we used a thin layer of $\mathrm{TiB}_{2}$ over Pyrex and again found that the performance was degraded. Here, the projectile penetrated $17.9 \mathrm{~g} / \mathrm{cc}$, about the same as for Pyrex alone.

\section{Computer Simulations}

We performed computer simulations of some of the experiments using GLO, a two-dimensional multi-material Eulerian finite-difference code under development at LLNL. The material parameters used to model the 4340 steel backing are those for Rc35 steel given in Appendix B.

\section{Simulations with Pyrex}

We selected Pyrex as the first tile material for the simulations. Previous experimental results suggested that the Pyrex fractures and breaks early in the penetration event, and so could be modeled as a broken material throughout the penetration event.

By assuming this, we achieve a significant simplification in the task of modeling ceramics numerically. The reason is that the change in the state from intact to broken is accompanied by a significant reduction in the magnitude of stress, whether fracture takes place in compression or tension. The resulting release of strain energy is propagated through the system with amplitude and period that are proportional to the finite-difference zone size. This numerical noise will, if the zone size is too large, be of sufficient amplitude to trigger the fracture of nearby zones. In contrast, when the material is in a single state (for Pyrex, always broken) the numerical solution is smooth.

The behavior of broken, hard materials is described by the Mohr-Coulomb friction model for granular media, well-known in the literature of soil and rock mechanics (for example ${ }^{8}$ ). The difference between the maximum principal stress, $\sigma_{1}$, and the minimum principal stress, $\sigma_{3}$, is given by

$$
\sigma_{1}-\sigma_{3}=\left(\sigma_{1}+\sigma_{3}\right) \sin \varphi
$$

where positive stress is compressive, and $\varphi$ is the friction angle. A somewhat 
simpler implementation, which does not require calculation of the principal stresses, is the extended von Mises criterion ${ }^{8}$

$$
Y=\alpha P
$$

where $Y$ is the equivalent stress and $P$ is the mean stress. When this criterion is fit to the compressive triaxial test $\left(\sigma_{1}>\sigma_{2}=\sigma_{3}\right)$, where $\sigma_{2}$ is the intermediate principal stress, it overestimates the measured strength of granular materials in shear $\left(\sigma_{2}=0\right)$ and extension $\left(\sigma_{1}=\sigma_{2}>\sigma_{3}\right)$. Nevertheless, we used this latter criterion (Eq. 2) in our computer simulations. So long as the parameter $\alpha$ is less than 1.5 , the minimum principal stress is always compressive.

A second feature that accompanies the shear of granular material is dilatancy 9 the increase in volume observed when a mass of dense, granular material undergoes shear at constant confining pressure. Although the plastic potential theory of von Mises will produce a plastic volume increase when the extended von Mises criterion (Eq. 2) is used as the potential surface, we have chosen to ignore dilatancy. Experiments on granular soils ${ }^{10}$ show that there is a specific porosity, which is a function of confining stress, that is achieved by a soil mass undergoing large shear deformation. In contrast, naive use of the plastic potential theory (associated flow rule) produces ever-increasing volume with shear deformation at constant normal stress. More complicated flow rules (or more complicated limit surfaces) are required to obtain physically realistic results, and require specification of additional parameters.

We found the parameter $\alpha$ in the extended von Mises criterion by the expedient of matching results of numerical simulations to experiments by Hord $^{11}$. There a short $\mathrm{W} 2$ projectile $(\mathrm{L} / \mathrm{D}=2.5)$ was fired into a confined Pyrex column at $1.5 \mathrm{~km} / \mathrm{s}$. Flash $\mathrm{x}$-rays were taken during the penetration event to mark the nose and tail position. Results of the experiments and two computer simulations with different values of $\alpha$ are shown in Fig. 4 . The final positions and residual projectile lengths are shown also. We chose $a=0.8$ for the remainder of the computer simulations for Pyrex. 
With this model for Pyrex, we performed computer simulations of the experimental geometry at $1.75 \mathrm{~km} / \mathrm{s}$, in advance of experiments with Pyrex. The comparison of the computed and measured residual penetration in steel is shown in Fig. 5. The surprisingly good agreement with experiment led us to examine the results of the computer simulations in more detail.

We show the velocity at the projectile nose and tail as a function of the nose position in Fig. 6 . There is a noticeable change in the nose (interface) velocity from the value characteristic of Pyrex to the value characteristic of steel over a distance in Pyrex that is approximately two projectile diameters. When we repeated the calculations, replacing the steel backup with aluminum and with tungsten, the transition region had the same two-diameter thickness, but with the final interface velocity being characteristic of aluminum or tungsten as can be seen in Fig. 7. This transition region has a significant effect on the differential efficiency of Pyrex, even when scaled to steel for all cases (Table 5.)

\section{Simulations with Aluminum Nitride}

The experimental results with aluminum nitride sufficiently intrigued us that we sought to model those experiments as well. Heard and Cline ${ }^{12}$ showed a transition from brittle to ductile failure in quasi-static triaxial compression tests when the confining stress $\sigma_{2}=\sigma_{3}$ exceeded $6 \mathrm{kbar}$ (pressure about $20 \mathrm{kbar}$ ). This suggested to use that perhaps at the highest velocity experiments, the mean

Table 5. Calculated influence of the backing metal on the performance of $20 \mathrm{~mm}$ thick Pyrex tiles at $1.75 \mathrm{~km} / \mathrm{s}$

\begin{tabular}{lllll}
\hline Backing metal & $\mathbf{P}_{0 \mathrm{~B}}, \mathbf{m m}^{\mathbf{a}}$ & $\mathbf{P}_{\mathrm{B}}, \mathbf{m m}$ & $\eta_{\mathrm{M}}{ }^{\mathbf{b}}$ & $\eta_{\mathrm{Ms}}{ }^{\mathrm{c}}$ \\
\hline Aluminum & 82.5 & 58.0 & 1.5 & 1.9 \\
Steel & 36.0 & 21.2 & 2.6 & 2.6 \\
Tungsten & 20.6 & 11.1 & 3.9 & 2.9 \\
\hline
\end{tabular}

${ }^{\circ} \mathrm{P}_{\mathrm{OB}}$ is the penetration in the backing metal without Pyrex

b The differential efficiency, $\eta_{M}$ is given by $\eta_{M}=\rho_{B}\left(P_{0 B}-P_{B}\right) /\left(\rho_{C} \Delta\right)$

where $\rho_{\mathrm{B}}$ is the backing metal density, $\rho_{\mathrm{C}}$ the tile density, and $\Delta$ the tile thickness..

' The differential efficiency scaled to steel, $\eta_{M S}$ is given by $\eta_{\mathrm{MS}}=\rho_{\mathrm{S}} \mathrm{P}_{\text {oS }} /\left(\rho_{\mathrm{B}} \mathrm{P}_{\mathrm{OB}}\right)$ where $\rho_{S}$ is the density of steel and $P_{\text {os }}$ the penetration in steel alone. 
stress in aluminum nitride was sufficiently large that the material was ductile, even at the strain rates of the impact test $\left(10^{5} / \mathrm{s}\right)$. We fit the quasi-static data ${ }^{12}$ by an extended von Mises surface $Y=f(P)$, and estimated the strength at the Hugoniot elastic limit to be $68 \mathrm{kbar}$, as shown in Fig. 8. Figure 9 shows the interpolated/extrapolated experimental penetration in the backup steel as a function of velocity for a $20 \mathrm{~mm}$ tile of AIN, together with calculations using the intact strength and the broken strength, where the value of $\alpha$ for broken AlN was arbitrarily taken to be the same value as was used for glass (Fig. 8).

From these results, it is our assessment that AIN is behaving substantially like a broken material at the lower two velocities, although we cannot rule out the possibility that there is a short time when the material retains its intact strength. In any event it is apparent that the calculations using the intact strength of AlN are incorrect at the lower two velocities.

When we examine detailed results of the two lower-velocity calculations that used the intact strength, the first $10 \%$ of plastic strain experienced by material in the path of the projectile is achieved at pressures below $30 \mathrm{kbar}$. At the strain rates achieved in the ballistic test, $10^{5} / \mathrm{s}$, we would estimate the brittle-ductile transition to occur at 30 to $40 \mathrm{kbar}$ ( $20 \mathrm{kbar}$ for the quasi-static tests). Thus we would infer that at the lower two velocities, the AlN fractures and is broken in the penetration path. The case for the higher velocity is less clear-cut. Most of the strain is achieved at pressures exceeding $35 \mathrm{kbar}$, although the strain from 2 to $4 \%$ is achieved at pressures as low as $25 \mathrm{kbar}$. At somewhat higher velocity, 3.5 $\mathrm{km} / \mathrm{s}$, we would anticipate that AlN in the penetration path would behave as a ductile, high strength material, and exhibit excellent resistance to penetration.

The calculations using the extended von Mises criterion for broken AIN are also not accurate except at the intermediate velocity. We note that the value of $\alpha$ chosen was the one for Pyrex, which gives results in substantial agreement with experiment in the velocity range 1.5 to $1.75 \mathrm{~km} / \mathrm{s}$, but is otherwise unsupported by independent experiment at different velocities (or confining pressure).

\section{Concluding remarks}

Our experimental results show that titanium diboride, boron carbide, and 
silicon carbide perform equally well when supported by a thick steel backing. They outperform aluminum nitride, Pyrex, and alumina at velocities below 2.0 . $\mathrm{km} / \mathrm{s}$. Interestingly, the two aluminas have about equal performance in this ballistic test for all three velocities.

At velocities above about $2.0 \mathrm{~km} / \mathrm{s}$ the aluminum nitride outperforms all the others. Moreover, Pyrex ranks with boron carbide, titanium diboride and silicon carbide at about $2.6 \mathrm{~km} / \mathrm{s}$ and may outperform them at higher velocities. Our compuier simulations for aluminum nitride suggest to us that the superior performance of aluminum nitride at the highest velocity is due to its retention through ductility of a substantial part of its strength at the high confining pressures experienced there, in contrast to the other ceramics, which are substantially broken at high velocity.

Our simulations of the Pyrex experiments show that a target material interface begins to influence the penetration process when the projectile nose is yet a significant distance away. This observation explains why thin layers of a facing material do not perform the same way as thicker ones. It is because the process is entirely within the transition region, where both materials are influencing the penetration process.

\section{Acknowledgments}

The authors thank Estella McGuire for performing the GLO computer simulations. This work was performed under the auspices of the U.S. Department of Energy by Lawrence Livermore National Laboratory under Contract No. W-7405-ENG-48 and the U. S. Army/DOE Memorandum of Understanding "Fundamentals of Penetration Program". This work was performed about ten years ago, and reported as UCRL-100710, July 20, 1989 with limited distribution. Mor recently, Steinberg used these experimental results to help develop a model for ceramics applied to titanium diboride, and reported those results in ${ }^{13}$. 


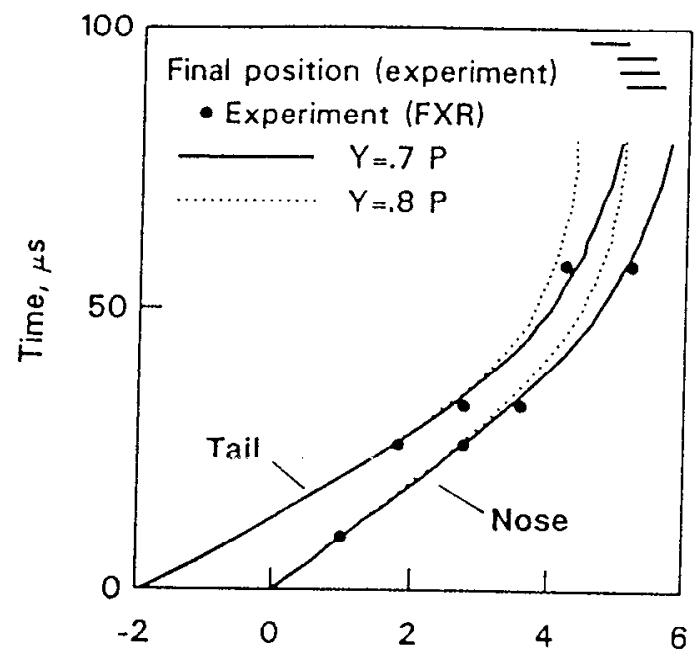

Eigure 4.

Position, cm

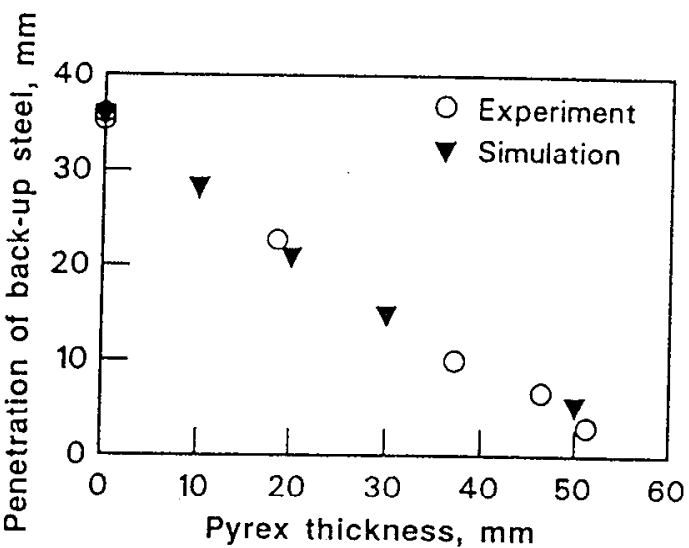

Eigure 5.

Residual penetration in the back-up steel, $\mathrm{Pb}$, as a function of Pyrex thickness, $\Delta$, from computer simulations and experiments at $1.75 \mathrm{~km} / \mathrm{s}$ using a blunt $L / D=4,25.4 \mathrm{~mm}$ long $\mathrm{W} 2$ projectile.

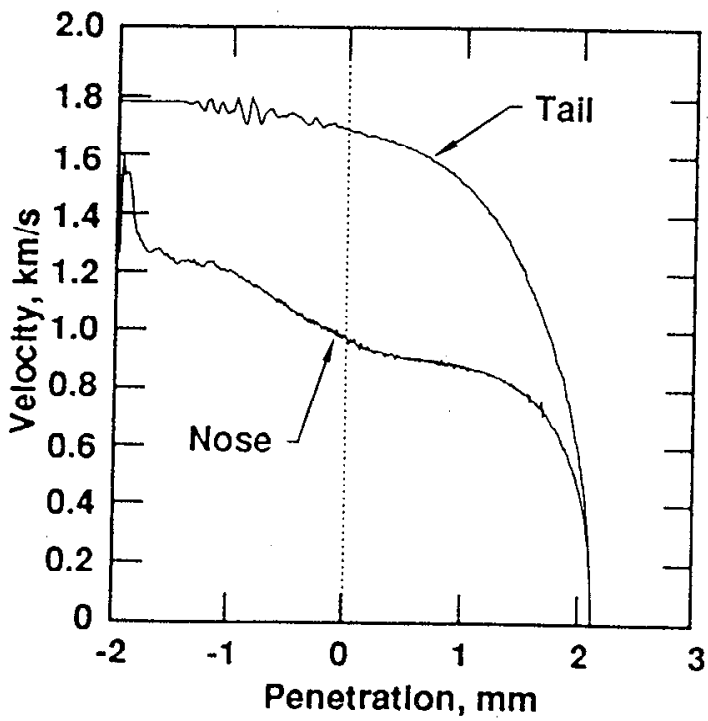

Eigure 6.

Calculated nose and tail velocities of a blunt, $L / D$ $=4,25.4 \mathrm{~mm}$ long projectile in a $20 \mathrm{~mm}$ Pyrex/steel target, as a function of the position of the projectile nose. Original glass/ steel interface is at position $=0$.

Positions of nose and tail as functions of time from ilash $x$-rays post-test $x$-rays. (short lines representing residual jectile length and posiare in upper rightnose and tail from computer simulations of the experilines). 

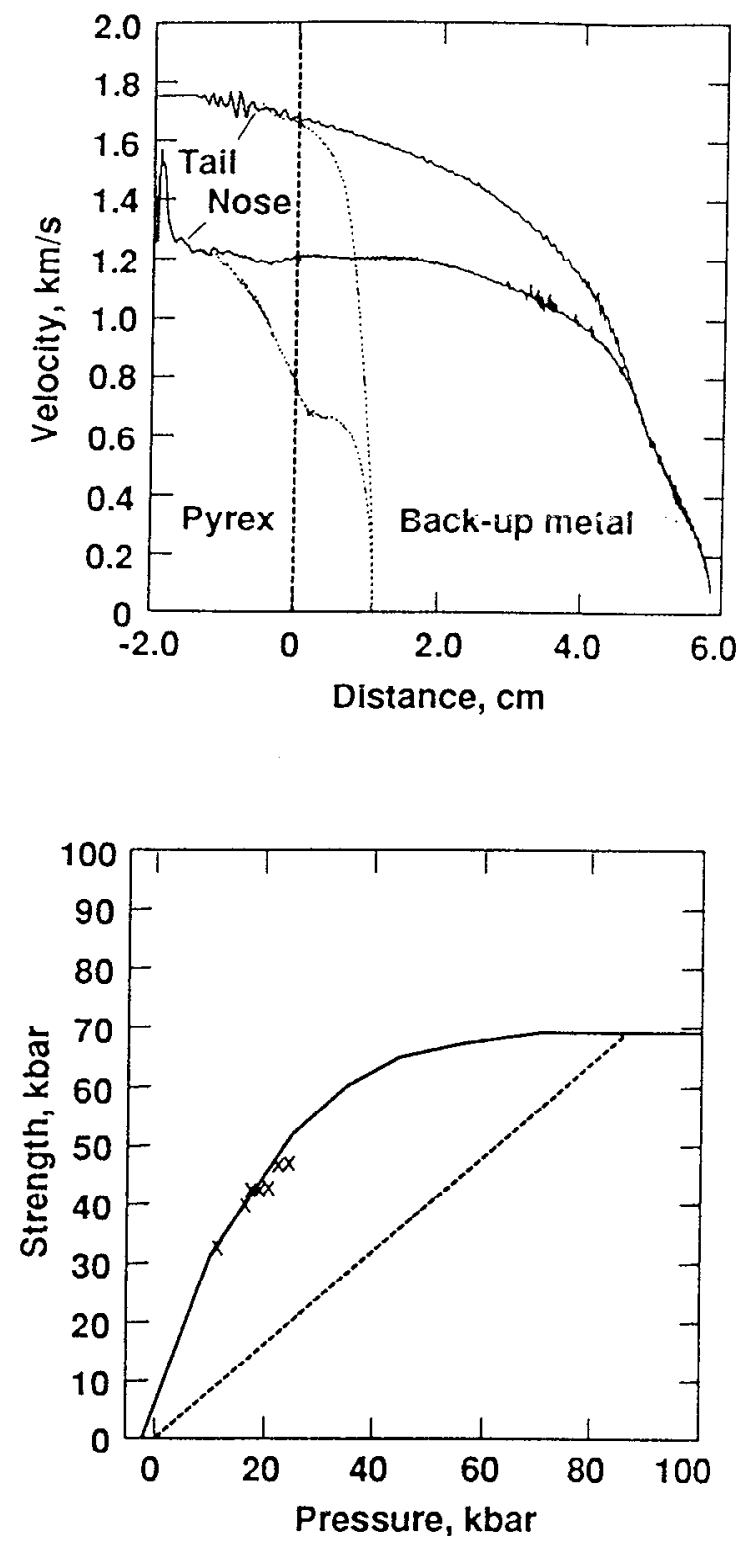

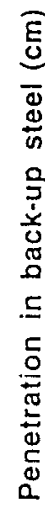

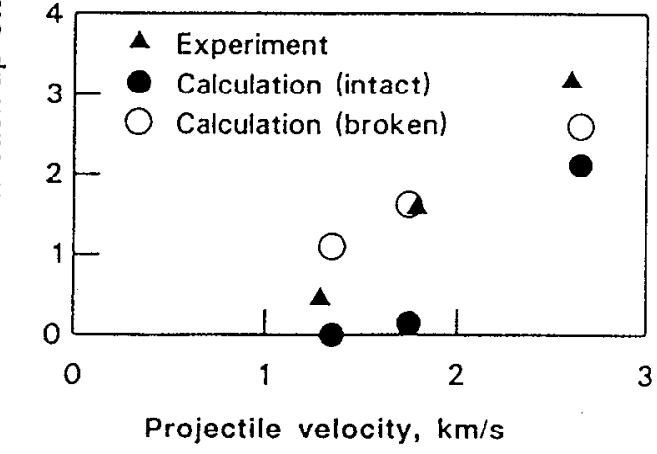

Figure?

Figure 8 .

Eigure 9.
Calculated nose and tail velocities, as in Fig. 7, except with the steel backup replaced by aluminum (dash) and tungsten (solid).
Measured strength of aluminum nitride (x), model fit to intact aluminum nitride (solid) and model for broken aluminum nitride (dash). The slope in the extended von Mises model was taken to be the same as for Pyrex.
Penetration in the back-up steel as a function of velocity for $20 \mathrm{~mm} A l N / s t e e l$ target from the experiment and from calculations using the intact and broken models. 


\section{Appendix A. Residual normal penetration in steel}

We present the experimental results for the normal residual penetration of a $6.35-\mathrm{mm}$ diameter by $25.4-\mathrm{mm}$ long tungsten projectile into the back-up steel. In the table below, the tile thickness, $\Delta$, is in $\mathrm{mm}$, the projectile velocity, $\mathrm{V}$, is in $\mathrm{km} / \mathrm{s}$, the obliquity, $\theta$, in degrees between the flight axis and the normal to the tile. The penetration normal to the steel surface, $P_{b}$, is in $\mathrm{mm}$.

Table A1. Experimental residual penetration

\begin{tabular}{|c|c|c|c|c|c|c|c|c|c|}
\hline Tile & $\Delta$ & V & $\theta$ & $P_{b}$ & Tile & $\Delta$ & V & $\theta$ & $P_{b}$ \\
\hline AD96 & 10.5 & 1.35 & 0 & 14.5 & AD85 & 6.2 & 1.33 & 0 & 18.5 \\
\hline AD96 & 15.1 & $1.35^{\mathrm{a}}$ & 0 & 11.1 & AD85 & 14.0 & 1.35 & 0 & 11.8 \\
\hline AD96 & 20.6 & 1.36 & 0 & 8.7 & AD85 & 22.1 & 1.35 & 0 & 7.5 \\
\hline AD96 & 30.2 & 1.36 & 0 & 4.0 & AD85 & 32.0 & 1.37 & 0 & 3.8 \\
\hline AD96 & 20.4 & 1.68 & 0 & 15.8 & AD85 & 6.2 & 1.75 & 0 & 31.0 \\
\hline AD96 & 31.7 & 1.72 & 0 & 6.4 & AD85 & 14.0 & 1.75 & 0 & 22.0 \\
\hline AD96 & 40.0 & 1.70 & 0 & 0.0 & AD85 & 29.9 & 1.75 & 0 & 10.0 \\
\hline AD96 & 40.4 & 1.80 & 0 & 0.5 & AD85 & 42.5 & 1.77 & 0 & 2.7 \\
\hline AD96 & 15.1 & 1.69 & 30 & 14.0 & AD85 & 20.5 & 2.50 & 0 & 33.6 \\
\hline AD96 & 29.9 & 1.74 & 30 & 5.5 & AD85 & 39.3 & 2.50 & 0 & 20.6 \\
\hline AD96 & 15.3 & 1.80 & 45 & 9.5 & AD85 & 59.1 & 2.50 & 0 & 2.6 \\
\hline AD96 & 25.0 & 1.72 & 45 & 0.0 & $\mathrm{SiC}$ & 10.0 & 1.37 & 0 & 13.9 \\
\hline AD96 & 10.5 & $1.74^{\mathrm{a}}$ & 60 & 6.7 & $\mathrm{SiC}$ & 15.1 & 1.36 & 0 & 2.0 \\
\hline AD96 & 15.2 & $1.74^{\mathrm{a}}$ & 60 & 4.1 & $\mathrm{SiC}$ & 20.0 & 1.37 & 0 & 0.0 \\
\hline AD96 & 20.0 & 1.74 & 60 & 0.0 & $\mathrm{SiC}$ & 30.1 & 1.31 & 0 & 0.0 \\
\hline AD96 & 15.1 & 2.63 & 0 & 39.2 & $\mathrm{SiC}$ & $20.0^{\mathrm{b}}$ & 1.69 & 0 & 14.3 \\
\hline AD96 & 30.1 & 2.63 & 0 & 27.8 & $\mathrm{SiC}$ & $20.0^{\mathrm{b}}$ & $1.75^{\mathrm{a}}$ & 0 & 14.5 \\
\hline AD96 & 51.3 & 2.62 & 0 & 5.9 & $\mathrm{SiC}$ & 29.5 & 1.77 & 0 & 5.7 \\
\hline $\mathrm{TiB}_{2}$ & 7.9 & 1.38 & 0 & 12.2 & $\mathrm{SiC}$ & 30.2 & 1.70 & 0 & 2.4 \\
\hline $\mathrm{TiB}_{2}$ & 10.0 & 1.31 & 0 & 3.7 & $\mathrm{SiC}$ & 40.0 & 1.74 & 0 & 0.0 \\
\hline $\mathrm{TiB}_{2}$ & 15.0 & 1.36 & 0 & 0.0 & $\mathrm{SiC}$ & 15.0 & 1.75 & 30 & 14.9 \\
\hline $\mathrm{TiB}_{2}$ & 20.0 & 1.37 & 0 & 0.0 & $\mathrm{SiC}$ & 31.3 & 1.78 & 30 & 1.0 \\
\hline $\mathrm{TiB}_{2}$ & 10.1 & 1.69 & 0 & 22.1 & $\mathrm{SiC}$ & 15.1 & 1.71 & 45 & 8.2 \\
\hline $\mathrm{TiB}_{2}$ & 14.9 & 1.70 & 0 & 7.3 & $\mathrm{SiC}$ & 25.0 & 1.81 & 45 & 0.0 \\
\hline $\mathrm{TiB}_{2}$ & 20.1 & 1.72 & 0 & 1.1 & $\mathrm{SiC}$ & 10.1 & 1.70 & 60 & 6.6 \\
\hline
\end{tabular}


Table A1. (concluded) Experimental residual penetration

\begin{tabular}{|c|c|c|c|c|c|c|c|c|c|}
\hline Tile & $\Delta$ & $\mathrm{V}$ & $\theta$ & $\mathbf{P}_{\mathrm{b}}$ & Tile & $\Delta$ & $\mathrm{V}$ & $\theta$ & $P_{b}$ \\
\hline $\mathrm{TiB}_{2}$ & 30.0 & 1.69 & 0 & 0.0 & $\mathrm{SiC}$ & 14.9 & 1.80 & 60 & 1.9 \\
\hline $\mathrm{TiB}_{2}$ & 10.1 & 1.70 & 30 & 19.5 & $\mathrm{SiC}$ & 20.0 & 1.69 & 60 & 0.0 \\
\hline $\mathrm{TiB}_{2}$ & 25.0 & 1.80 & 30 & 0.0 & $\mathrm{SiC}$ & 30.1 & 2.62 & 0 & 18.2 \\
\hline $\mathrm{TiB}_{2}$ & 7.7 & 1.73 & 45 & 15.4 & $\mathrm{SiC}$ & 39.9 & 2.68 & 0 & 15.6 \\
\hline $\mathrm{TiB}_{2}$ & 20.0 & 1.69 & 45 & 0.0 & $\mathrm{SiC}$ & 59.7 & 2.64 & 0 & 0. \\
\hline $\mathrm{TiB}_{2}$ & 7.8 & 1.80 & 60 & 5.6 & $\mathrm{~B}_{4} \mathrm{C}$ & 10.4 & 1.79 & 0 & 28.3 \\
\hline $\mathrm{TiB}_{2}$ & $1 b .0$ & 1.81 & $60^{\circ}$ & 0.0 & $\mathrm{~B}_{4} \mathrm{C}$ & 19.3 & $1.74^{\mathrm{a}}$ & 0 & 19.8 \\
\hline $\mathrm{TiB}_{2}$ & 20.1 & 2.63 & 0 & 34.5 & $\mathrm{~B}_{4} \mathrm{C}$ & 28.8 & 1.78 & 0 & 9.8 \\
\hline $\mathrm{TiB}_{2}$ & 24.9 & 2.69 & 0 & 29.8 & $\mathrm{~B}_{4} \mathrm{C}$ & 28.0 & 1.79 & 30 & 3.3 \\
\hline $\mathrm{TiB}_{2}$ & 30.3 & 2.63 & 0 & 17.8 & $\mathrm{~B}_{4} \mathrm{C}$ & 17.6 & 1.77 & 60 & 2.2 \\
\hline $\mathrm{TiB}_{2}$ & 40.0 & 2.63 & 0 & 9.6 & $\mathrm{~B}_{4} \mathrm{C}$ & 10.4 & 1.28 & 0 & 13.3 \\
\hline AlN & 9.7 & 1.25 & 0 & 10.1 & $\mathrm{~B}_{4} \mathrm{C}$ & 15.2 & 1.22 & 0 & 3.8 \\
\hline AlN & 14.3 & 1.30 & 0 & 8.9 & $\mathrm{~B}_{4} \mathrm{C}$ & 19.2 & 1.29 & 0 & 0.0 \\
\hline AlN & 19.6 & 1.31 & 0 & 4.3 & $\mathrm{~B}_{4} \mathrm{C}$ & 38.9 & 2.61 & 0 & 14.5 \\
\hline AlN & 9.9 & 1.79 & 0 & 27.5 & $\mathrm{~B}_{4} \mathrm{C}$ & 58.6 & 2.61 & 0 & 5.6 \\
\hline AlN & 19.7 & 1.79 & 0 & 14.3 & Pyrex & 18.5 & 1.80 & 0 & 22.7 \\
\hline AlN & 28.8 & 1.80 & 0 & 8.5 & Pyrex & 37.2 & 1.78 & 0 & 10.0 \\
\hline AlN & 37.0 & 1.79 & 0 & 0.0 & Pyrex & 46.4 & 1.78 & 0 & 6.7 \\
\hline AlN & 28.2 & 1.76 & 30 & 1.6 & Pyrex & 51.3 & 1.80 & 0 & 3.0 \\
\hline AlN & 17.5 & 1.78 & 60 & 0.0 & Pyrex & 39.4 & 2.64 & 0 & 28.5 \\
\hline AlN & 30.3 & 2.61 & 0 & 19.3 & Pyrex & 58.9 & 2.65 & 0 & 16.3 \\
\hline AlN & 39.5 & 2.58 & 0 & 8.3 & & & & & \\
\hline
\end{tabular}

a Velocity estimated from the powder load

${ }^{b}$ The facing on the first of these two shots was a single $20 \mathrm{~mm}$ plate. The facing for the second was two 10 mm plates bonded together. 
Table A2. Penetration depth of normal impazts into the back-up steel alone.

\begin{tabular}{ll}
\hline $\mathrm{V}$ & $\mathrm{P}_{\mathrm{b}}$ \\
\hline $1.34^{\mathrm{a}}$ & 26.8 \\
1.34 & 27.0 \\
1.34 & 27.0 \\
1.35 & 27.8 \\
1.35 & 28.5 \\
$1.74^{\mathrm{a}}$ & 35.3 \\
1.77 & 36.0 \\
2.62 & 61.1 \\
2.50 & 43.8 \\
\hline
\end{tabular}

\section{Appendix B. Characterization of 4340 steel}

Four-inch diameter billets of 4340 steel were quenched and tempered to achieve nominal Rockwell hardness of Rc35, Rc40, and Rc45. Three 0.5-inch diameter standard tensile specimens (2-inch gauge length, 6 inches long) were machined from each heat treatment, designated 35-1, 35-2, 35-3, 40-1, etc. The specimens were tested in tension on a 56,000 pound Instron machine according to ASTM standard E8 at room temperature. Crosshead speed was $0.01 \mathrm{in} / \mathrm{min}$., except for specimens 35-1, 35-2, 40-1, and 45-1, which were tested at 0.005 $\mathrm{in} / \mathrm{min}$. Gauge extension was measured with an Instron 2 "-50\% extensometer, and load-elongation plots were produced for each test. In addition, a Zygo laser was used to scan 1.7 inches of the 2-inch gauge length at a speed of $0.26 \mathrm{in} / \mathrm{s}$ on an interval determined by the deviation of the minimum diameter from the original diameter, ranging from once every five minutes initially to once every 20 sec when the diameter had reduced by $30 \%$. During each sweep, approximately 90 diameter determinations were made and recorded digitally, together with the load at the beginning and end of each sweep. 
We followed the procedure of Norris et al. ${ }^{14}$ to determine the work-hardening functional dependence of the three heat treatments. In that procedure, a computer simulation of the tension test is performed (we used HEMP'5) with an initial guess at the work-hardening. Results of the computer simulations and experiments are compared, and the work hardening function revised until satisfactory agreement is reached. The results are shown in Fig. B1-B3 for the three heat treatments. In those figures true strain is $-2 \ln \left(D / D_{0}\right)$ where $D$ is the minimum diameter. Engineering stress is the load per unit area of the original minimum cross-section. The functional form chosen is

$$
Y=Y_{0}\left(1+\beta \varepsilon^{p}\right)^{n}
$$

where $Y$ is the equivalent stress, and $\varepsilon^{p}$ is the equivalent plastic strain. The fitted parameters are given in Table B1.

Table B1. Parameters for the flow stress of 4340 Steel

\begin{tabular}{ccccc}
\hline $\begin{array}{l}\text { Nominal } \\
\text { hardness, Rc }\end{array}$ & $\begin{array}{c}\text { Measured } \\
\text { hardness, } \mathbf{R c}\end{array}$ & $\mathbf{Y}_{0}$, kbar & $\beta$ & $\mathrm{n}$ \\
\hline 35 & 34 & 10.3 & 125 & 0.0700 \\
40 & 40 & 12.9 & 282 & 0.0 .389 \\
45 & 43 & 13.2 & 580 & 0.0350 \\
\hline
\end{tabular}




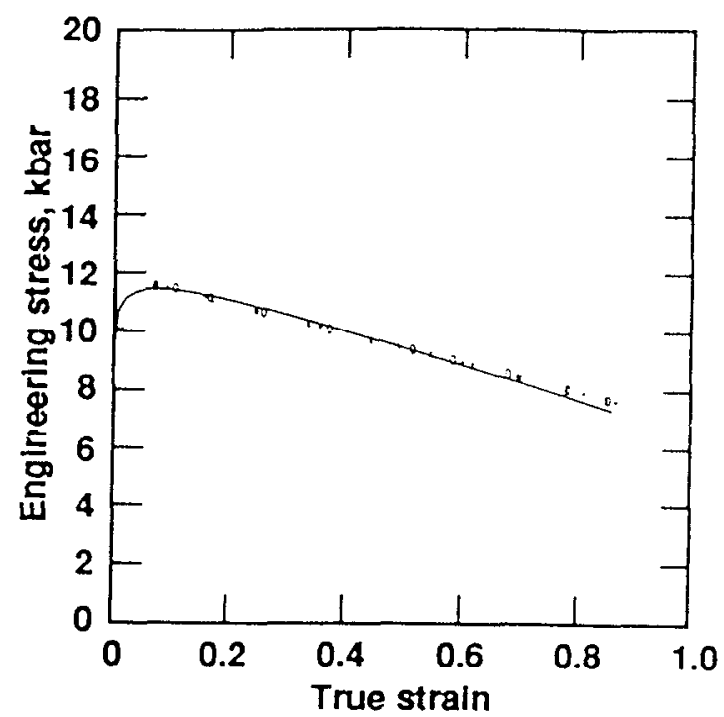

Eigure A1. Engineering stress as a function of true strain for 4340 steel, Rc35. Solid curve is from the computer simulation. Experimental points are from specimens $35-1(x), 35-2(0)$, and $35-$ $3(+)$.

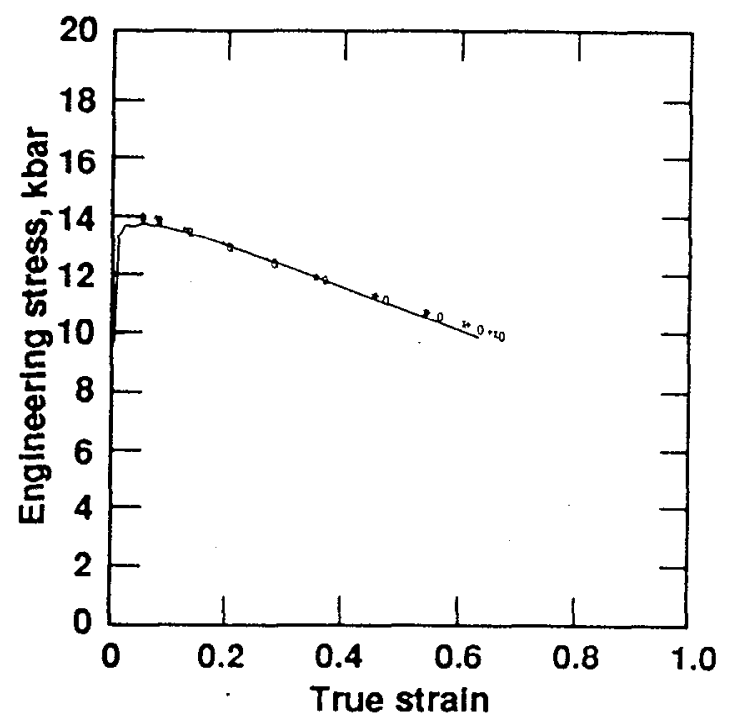

Eigure A2.

Engineering stress as a function of true strain for 4340 steel, Rc40. Solid curve is from the computer simulation. Experimental points are from specimens 40-1 (x), 40-2 (0), and 40$3(+)$.

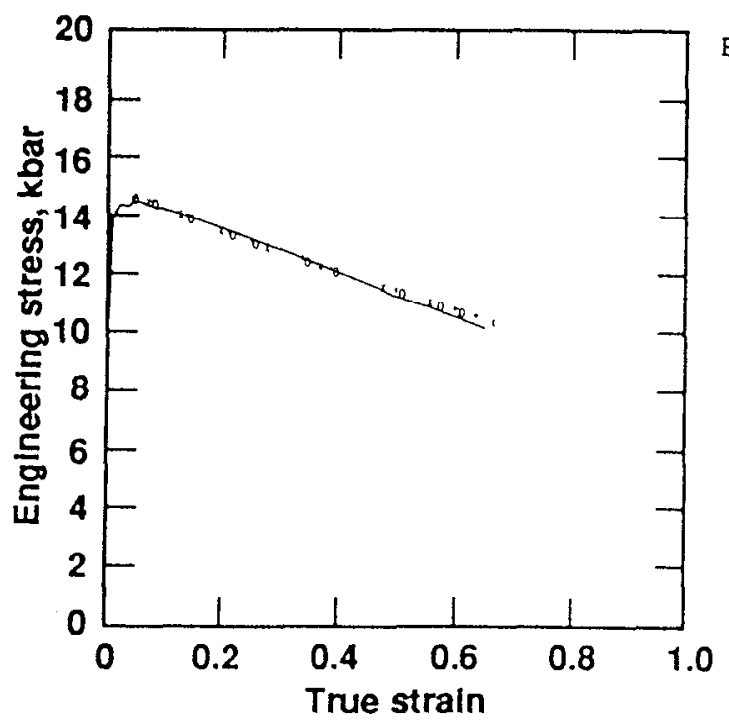

Figure A3.

Engineering stress as a function of true strain for 4340 steel, Rc45. Solid curve is from the computer simulation. Experimental points are from specimens 45-1 (x), 45-2 (o), and 45$3(+)$. 


\section{References}

1. M. L. Wilkins, C. Honodel, and D. Sawle, "An approach to the study of light armor," Lawrence Livermore National Laboratory, Livermore, CA Report No. UCRL-50284, June 13, 1967.

2. M. L. Wilkins, "Second progress report of the light armor program," Lawrence Livermore National Laboratory, Livermore, CA Report No. UCRL-50349 Rev. 1, 1967.

3. M. L. Wilkins, "Third progress report of the light armor program," Lawrence Livermore National Laboratory, Livermore, CA Report No. UCRL-50460, July 9, 1968.

4. M. L. Wilkins, C. F. Cline, and C. A. Honodel, “Fourth progress report of light armor program," Lawrence Livermore National Laboratory, Livermore, CA Report No. UCRL-50694, 1969.

5. M. L. Wilkins, "Mechanics of penetration and perforation," Int. J. Engrg. Sci., vol. 16, pp. 793-807, 1978.

6. M. L. Wilkins and J. E. Reaugh, "Computer simulations of ballistic experiments," Lawrence Livermore National Laboratory, Livermore, CA Report No. UCRL-95774, January 23, 1987.

7. D. E. Gray, "American Institute of Physics Handbook," , Third ed. New York: McGraw Hill Book Company, 1972.

8. A. W. Bishop, "Shear strength parameters for undisturbed and remoulded soil specimens," in Stress-Strain Behavior of Soils, R. H. G. Parry, Ed. Henly-onThames: G. T. Foulis \& Co. Ltd., 1972, pp. 7-11.

9. O. Reynolds, "On the dilatency of media composed of rigid particles in contact, with experimental illustrations," Phil. Mag. S., vol. 5, pp. 20, 1885.

10. C. P. Wroth and R. H. Bassett, "A stress-strain relationship for the shearing behavior of a sand," Geotechnique, vol. 15, pp. 32-56, 1965.

11. B. L. Hord, Personal Communication, 1986. 
12. H. C. Heard and C. F. Cline, "Mechanical behavior of polycrystalline BeO, $\mathrm{Al}_{2} \mathrm{O}_{3}$ and $\mathrm{AlN}$ at high pressure," Mats. Science, vol. 15, pp. 1889-1897, 1980.

13. D. J. Steinberg and R. E. Tipton, "A new fracture model for ceramics," Lawrence Livermore National Laboratory, Livermore, CA Report No. UCRL-JC116953, March 14, 1994.

14. D. N. Norris, B. Moran, J. K. Scudder, and D. F. Quinones, "A computer simulation of the tension test," J. Mech. Phys. Solids, vol. 26, pp. 1-19, 1968.

15. M. L. Wilkins, "Calculation of Elastic-Plastic Flow," in Methods of Computational Physics, vol. 3, B. Alder, S. Fernbach, and M. Rotenberg, Eds. New York: Academic, 1964, pp. 211-263. 